\title{
Characterization and optimization of endogenous lipid accumulation in Chlorella vulgaris SDEC-3M ability to rapidly accumulate lipid for reversing nightly lipid loss
}

\author{
Feng Qi ${ }^{1,2,5}$, Haiyan Pei ${ }^{2,3^{*}} \mathbb{D}$, Ruimin Mu ${ }^{1,5}$, Guixia Ma ${ }^{1}$, Daoji Wu ${ }^{1}$ and Qiang $\mathrm{Han}^{4}$
}

\begin{abstract}
Background: During inevitable light/dark cycle, lipid productivity of outdoor microalgae photoautotrophic cultivation is lowered by nightly biomass and lipid loss. To minimize, or even reverse the nightly lipid loss, it was expected that lipid accumulation would not cease, even if at night. Without relying on photosynthesis and organic matter in media, endogenous lipid accumulation that consumes energy and carbon sources derived from cells themselves, namely endogenous accumulation, is the only way for lipid production. The main aims of the present study was to characteristic endogenously accumulated lipid, confirm feasibility to reverse nightly lipid loss, and determine optimal conditions and its quality suitability for biodiesel feedstock production under stress conditions.
\end{abstract}

Results: Chlorella vulgaris SDEC-3M ability to rapidly accumulated lipid under stress conditions was cultivated for $12 \mathrm{~h}$ in darkness, and the effects of various conditions on lipid accumulation and biomass loss were analyzed. Under non-stress conditions, lipid contents dropped. Under certain stress conditions, conversely, the lipid contents were substantially improved so that net nightly endogenous lipid accumulation was observed. Under the optimal conditions (aeration mode with $0.10 \mathrm{vvm}$ and $15 \% \mathrm{CO}_{2}, 5-10 \mathrm{mg} \mathrm{L}^{-1}$ of $\mathrm{NO}_{3}{ }^{-} \mathrm{N}, 30-35^{\circ} \mathrm{C}$, approximate $2500 \mathrm{mg} \mathrm{L}^{-1}$ of biomass), the lipid content was doubled and increased lipid was approximately $180 \mathrm{mg} \mathrm{L}^{-1}$. Among stress conditions, N-deficiency had the most significant effect on endogenous lipid accumulation, and the optimum results were characterized under relatively low-N concentrations. Higher consistency between loss in carbohydrate and gain in lipid confirmed accumulated lipid endogenously conversed from carbohydrate. Based on the analyses of fatty acids profiles and prediction of kinematic viscosity, specific gravity, cloud point, cetane number and iodine value, it was confirmed that the quality of lipid obtained under optimal conditions complied with biodiesel quality standards.

Conclusion: Via triggering endogenous lipid accumulation by stress conditions, even in darkness, SDEC-3M can synthesize enough lipid suitable for biodiesel feedstock. It implies that the lipid accumulation phase in two-phase strategy can be scheduled at night, and following biomass production stage in light, which should be a solution to improve the lipid yield and quality of large-scale outdoor photoautotrophic microalgae cultivation for biodiesel production.

Keywords: Nightly lipid loss, Endogenous lipid accumulation, Microalgae, Light-NR/dark-ND process, Biodiesel

\footnotetext{
*Correspondence: haiyanhup@126.com

${ }^{3}$ School of Environmental Science and Engineering, Shandong University,

Qingdao 266237, China

Full list of author information is available at the end of the article
} 


\section{Background}

Concerns about limited fossil fuel reserves and climatic change have greatly aroused the interest of researchers for alternative energy sources. In this context, algaebased biodiesel becomes a focus due to its renewable and environment friendly properties [1-5]. Profiting from free carbon source from $\mathrm{CO}_{2}$ and free energy source for sunlight, little contamination, and its carbon neutrality, outdoor photoautotrophic cultivation has always been the main stream for microalgae biodiesel production [6-8]. However, light/dark cycle is an issue that must be considered in microalgal outdoor culture. Because photosynthesis is suspended and respiration keeps going at night, nightly biomass loss, and therefore, lipid loss become unavoidable [9-11]. Furthermore, the lipid accumulation was also delayed due to the imbalance of the metabolites related to lipid biosynthesis during light/dark cycle [7]. As a result, up to $35 \%$ loss in biomass [9] and $26 \%$ loss in triglyceride (TAG) [12] were observed in some microalgaes during darkness, which dramatically lowered the lipid productivity. For the purpose of low-cost algae-based biodiesel production, minimization and even reversal of nightly lipid loss in cells is necessary $[13,14]$. Although a lightautotrophic/dark-heterotrophic cyclic cultivation was proposed to prevent nightly biomass from loss [10], it risks possible contamination, high cost of carbon source, and uncontrollable concentrations of organic substrates. Other researchers attempted to reduce the nightly biomass and lipid loss through optimizing cultivation conditions, such as controlling daytime and nighttime temperatures or avoiding mixing at night [9$11]$. However, the attempts could not completely prevent any lipid loss.

Exposed to stress conditions, microalgae can be induced to accumulate lipid for biodiesel industry $[5,13-$ 15]. The strategy has an associated problem that inhibits cell growth to decrease biomass [14]. The most feasible strategy to overcome this bottleneck is two-stage strategy, with a biomass production stage under suitable growth conditions, followed by a lipid accumulation stage under stress conditions [1, 16-19]. As the most common stress conditions used in the two-stage strategy [1,20], N-deficiency caused by a medium excluding nitrogen or containing little nitrogen $[12,14,19,21]$ can induce cellular carbon flux is changed to lipid synthesis instead of carbohydrate and proteins [22], which drastically increases the lipid content in microalgae. It is hypothesized that induction by stress conditions accompanies with night, when the growth of microalgae is always ceased, can minimize, and even reverse the negative effect of nighttime on the lipid accumulation. Based on this hypothesis, a batch process comprising a light/dark cycle in cooperation with an $\mathrm{N}$-rich/N-deficient cycle (light-NR/dark-ND) process modified two-stage strategy [19].

There are three key issues to be solved for a design of light-NR/dark-ND process. First, without relying on photosynthesis and organic matter in media, lipid synthesis in darkness consumes or reserves energy and carbon sources derived only from cells themselves, namely endogenous lipid accumulation. In the reported overwhelming studies, lipid content elevated by $\mathrm{N}$-deficiency was observed in light, while the phenomenon was found in darkness only by a few researchers [7, 9, 20]. Thus, the feasibility of nightly endogenous lipid accumulation should be confirmed. Second, for most of the microalgae species, the obvious effects of lipid accumulation were usually observed within 2-6 days [21, 23]. For coordinating with light/dark cycle, however, noticeable endogenous lipid accumulation should occur just during about 12-h darkness. Fortunately, it was found that the lipid content of Chlorella was rapidly elevated only during $12 \mathrm{~h}$ N-deficiency, merely in light $[19,20]$. Such rapid elevation of lipid content in microalgae cells occuring during darkness should be determined. The lipid accumulation can be improved by optimizing several cultivation conditions, such as temperature, light intensity, nutrient concentration and so on [5]. Thus, optimal conditions should also be determined. Carbon and energy sources of accumulated lipid should also be examined. Finally, Shekh et al. [18] found that stress-induced lipids were not suitable as biodiesel feedstocks, but some contrary findings were subsequently reported $[16,19,24]$. Thus, to confirm the suitability as feedstocks for biodiesel production, the quality of the endogenously accumulated lipid should be characterized via its fuel properties, such as kinematic viscosity (KV), specific gravity (SG), cloud point $(\mathrm{CP})$, cetane number $(\mathrm{CN})$, iodine value (IV). In view of the difficulty of direct measurements in smaller scale cultivation, the fuel properties were often indirectly determined. For example, based on the equations deduced by Hoekman et al. [21], these fuel properties can be predicted to be evaluated by fatty acid profiles that were relatively easy to measure $[25,26]$.

Chlorella vulgaris SDEC-3M is a UV mutant accumulating abundant carbohydrates (more than $40 \%$ of biomass) under N-rich conditions [27]. Its lipid content was almost doubled during $12 \mathrm{~h} \mathrm{~N}$-deficiency, and the dominance of endogenous lipid accumulation has been proved by a comparison between increments of biomass and lipid [19]. The rapidly accumulating lipid suitable as biodiesel feedstocks was also confirmed [19]. However, the above results were all observed in light. Thus, as a potential model algae employed for light-NR/dark-ND process, its lipid yield and quality accumulated in darkness should be characterized. 
In the present study, as a model microalgal strain, $C$. vulgaris SDEC-3M was cultivated for $12 \mathrm{~h}$ in darkness. Effects of the different conditions, such as blending mode, $\mathrm{CO}_{2}$ level, aeration rate, $\mathrm{NO}_{3}{ }^{-}-\mathrm{N}$ concentration, temperature and initial biomass concentration, lipid content, and lipid accumulation were characterized. The effect of different $\mathrm{NO}_{3}{ }^{-} \mathrm{N}$ concentrations on carbohydrate content was also characterized. Based on these results, the feasibility of endogenous microalgal lipid accumulation in darkness and potential of lipid production under optimal cultivation conditions were confirmed, and its rough pathway was preliminary determined. Through fatty acid profile analysis, further, several properties of biodiesel derived from SDEC-3M were estimated to analyze their standard -compliance as biodiesel feedstocks. These findings provided new insight into design the light-NR/dark-ND process for enhancing microalgal lipid production during light/dark cycle, which was inevitable in outdoor cultivation.

\section{Methods}

\section{Microalgae, culture medium, and aeration}

As a potential $\mathrm{CO}_{2}$ biofixation and biofuel production candidate, C. vulgaris SDEC-3M was obtained from Shandong Provincial Engineering Centre on Environmental Science and Technology (SDEC) [27]. Seven modified SE media were used (denoted SE1 to SE7). Each $1 \mathrm{~L}$ of medium contained $75 \mathrm{mg}$ of $\mathrm{K}_{2} \mathrm{HPO}_{4} \cdot 3 \mathrm{H}_{2} \mathrm{O}$, $75 \mathrm{mg}$ of $\mathrm{MgSO}_{4} \cdot 7 \mathrm{H}_{2} \mathrm{O}, 25 \mathrm{mg}$ of $\mathrm{CaCl}_{2} \cdot 2 \mathrm{H}_{2} \mathrm{O}, 175 \mathrm{mg}$ of $\mathrm{KH}_{2} \mathrm{PO}_{4}, 25 \mathrm{mg}$ of $\mathrm{NaCl}, 5 \mathrm{mg}$ of $\mathrm{FeCl}_{3} \cdot 6 \mathrm{H}_{2} \mathrm{O}, 1 \mathrm{~mL}$ of $\mathrm{A}_{5}$ solution, $1 \mathrm{~mL}$ of Fe-EDTA, and $958 \mathrm{~mL}$ of deionized water. Each $1 \mathrm{~L}$ of $\mathrm{A}_{5}$ solution contained $2.86 \mathrm{~g}$ of $\mathrm{H}_{3} \mathrm{BO}_{3}$, $1.81 \mathrm{~g}$ of $\mathrm{MnCl}_{2} \cdot 4 \mathrm{H}_{2} \mathrm{O}, 0.22 \mathrm{~g}$ of $\mathrm{ZnSO}_{4} \cdot 4 \mathrm{H}_{2} \mathrm{O}, 79 \mathrm{mg}$ of $\mathrm{CuSO}_{4} \cdot 5 \mathrm{H}_{2} \mathrm{O}$, and $39 \mathrm{mg}$ of $(\mathrm{NH})_{6} \mathrm{Mo}_{7} \mathrm{O}_{24} \cdot 4 \mathrm{H}_{2} \mathrm{O}$. Each $1 \mathrm{~L}$ of Fe-EDTA solution contained $10 \mathrm{~g}$ of $\mathrm{Na}_{2}$ EDTA, $0.81 \mathrm{~g}$ of $\mathrm{FeCl}_{3} \cdot 6 \mathrm{H}_{2} \mathrm{O}$, and $500 \mathrm{~mL}$ of $0.1 \mathrm{M} \mathrm{HCl}$. Additionally, into each $1 \mathrm{~L}$ of SE2, SE4, SE5, SE6, and SE7 media were added 12.50, 31.25, 62.50, 125.00, and $250.00 \mathrm{mg} \mathrm{NaNO}$, respectively. Further, $40 \mathrm{~mL}$ of soil extract, which was supernatant filtered from boiled soil solution, was added to SE3, SE4, SE5, SE6, and SE7 media. The monitored values of $\mathrm{NO}_{3}{ }^{-}$-N concentration, and absence or presence of soil extract in the seven fresh media are shown in Table 1.

Aeration was carried out by air or by mixtures of air and $\mathrm{CO}_{2}$ in different proportions that were prepared in industrial cylinders. The flow rates were adjusted by gas flow meters (Sevenstar, China).

\section{Pre-cultivation and re-suspension}

Diluted to initial optical densities at wavelength $686 \mathrm{~nm}$ $\left(\mathrm{OD}_{686}\right)$ of $0.35 \mathrm{~cm}^{-1}$ (biomass concentration of approximately $90 \mathrm{mg} \mathrm{L}^{-1}$ ) with fresh SE7 medium, SDEC$3 \mathrm{M}$ was inoculated in photobioreactors (ID, $120 \mathrm{~mm}$; height, $300 \mathrm{~mm}$; working volume, $2.5 \mathrm{~L})[19,28]$. The
Table $1 \mathrm{NO}_{3}{ }^{-} \mathrm{N}$ concentrations and absence or presence of soil extract in the fresh media used in the present study

\begin{tabular}{lll}
\hline Medium & $\begin{array}{l}\mathbf{N O}_{\mathbf{3}}{ }^{-}-\mathbf{N} \text { concentration } \\
\left(\mathbf{m g ~ L}^{-\mathbf{1}}\right)^{\mathbf{a}}\end{array}$ & Soil extract $^{\mathbf{b}}$ \\
\hline SE1 & 0 & - \\
SE2 & 2.06 & - \\
SE3 & 2.00 & + \\
SE4 & 6.52 & + \\
SE5 & 11.43 & + \\
SE6 & 21.13 & + \\
SE7 & 42.81 & + \\
\hline
\end{tabular}

a Monitoring data, $\mathrm{NO}_{3}{ }^{-}-\mathrm{N}$ from $\mathrm{NaNO}_{3}$ or nitrate in soil extract

b "-" represents media without soil extract, and "+" represents media with soil extract

photobioreactors were placed in a phytotron at $25 \pm 1{ }^{\circ} \mathrm{C}$ under continuous $67.5 \mu \mathrm{mol} \mathrm{m} \mathrm{m}^{-2} \mathrm{~s}^{-1}$ illumination provided by six $40 \mathrm{~W}$ fluorescent daylight lamps on a panel. $15 \% \mathrm{CO}_{2}(\mathrm{v} / \mathrm{v})$ was bubbled into each photobioreactor through two 0.5 inch air stone diffusers at a flow rate of $0.008 \mathrm{vvm}$ (volume gas per volume culture per minute). The microalgae with $11.56 \%$ of lipid content and $42.58 \%$ of carbohydrates content were harvested after 4 days' preculturing. The cultures were centrifuged into microalgal pellets at $4000 \mathrm{rpm}$ and $-3{ }^{\circ} \mathrm{C}$ for $10 \mathrm{~min}$. The microalgal pellets were washed to desalinate them and centrifuged into microalgal pellets again. Finally, the microalgal pellets washed were resuspended with the specific medium mentioned above, to regenerate culture suspension.

\section{Cultivation}

Aside from a small portion retained as a control, most microalgae culture suspension regenerated was transferred into a $500 \mathrm{~mL}$ gas-washing bottle for "aeration" cultivation or sealed glass bottle with a lid for "standing" (i.e. quiescent) or "shaking" cultivation. These bottles were then covered with black cloth to protect from light in a constant temperature incubator for standing or aeration cultivation, or a shaking incubator for shaking cultivation at $130 \mathrm{rpm}$ for $12 \mathrm{~h}$ in darkness.

To study the effect of blending mode, the microalgae were cultivated in standing mode without shake or aeration, shaking mode at $130 \mathrm{rpm}$, and aeration mode with $0.10 \mathrm{vvm}$ of air, respectively, and all at $25^{\circ} \mathrm{C}$ in SE3 medium. To study the effect of $\mathrm{CO}_{2}$ level, the microalgal broths were aerated with $0.10 \mathrm{vvm}$ of air (approximately $0.04 \% \mathrm{CO}_{2}$ ), and mixtures containing $1 \%, 5 \%, 15 \%$, and $25 \% \mathrm{CO}_{2}$, respectively, all at $25{ }^{\circ} \mathrm{C}$ in SE3 medium. To study the effect of aeration rate, the microalgae broths were aerated at $0,0.04,0.06,0.10,0.20$ and $0.32 \mathrm{vvm}$ with a mixture containing $15 \% \mathrm{CO}_{2}$, respectively, 
likewise at $25{ }^{\circ} \mathrm{C}$ in SE3 medium. To study the effect of $\mathrm{NO}_{3}{ }^{-}-\mathrm{N}$ concentration and presence of soil extract in the medium, the microalgae were resuspended with the seven media, respectively, cultivated at $25{ }^{\circ} \mathrm{C}$, and aerated at $0.10 \mathrm{vvm}$ with a mixture containing $15 \% \mathrm{CO}_{2}$. To study the effect of temperature, the microalgae were respectively cultivated at 10,15, 20, 25, 30, 35 and $40{ }^{\circ} \mathrm{C}$, in SE4 medium, and aerated at $0.10 \mathrm{vvm}$ with a mixture containing $15 \% \mathrm{CO}_{2}$. The above experiments were all low-density cultivation. To study the effect of biomass concentration, the microalgae were respectively cultivated with 701.2 (low-density, LD), 1461.5 (mid-density, MD), 2434.6 (high-density, HD) and 4869.2 (super-high-density, SD) $\mathrm{mg} \mathrm{L}^{-1}$ of initial biomass concentration, in SE4 medium, at $30{ }^{\circ} \mathrm{C}$, and aerated at $0.10 \mathrm{vvm}$ with a mixture containing $15 \% \mathrm{CO}_{2}$. The initial lipid contents were determined as approximately $11.7 \%$. All treatments were triplicate.

\section{Measurement methodology}

The retained microalgae culture suspensions were centrifuged to form microalgal pellets at $4000 \mathrm{rpm}$ at $-3{ }^{\circ} \mathrm{C}$ for $10 \mathrm{~min}$, as well as broths following $12 \mathrm{~h}$ darkness. Before centrifugation, the broths were sampled for cell observation using a microscope (CX31, Olympus, Japan), for determination of dissolved oxygen (DO) by an HQ-30D probe (Hach, USA) and pH by PHS-3C $\mathrm{pH}$ meter (Leici, shanghai, China). The pellets were then washed twice with distilled water to desalinate, dried, weighed, and ground into powder [24]. Biomass concentration $\left(\mathrm{mg} \mathrm{L}^{-1}\right)$ was obtained by comparing the dry biomass to the effective broth volume. Microalgal lipids were extracted by a chloroform/methanol (2:1, $\mathrm{v} / \mathrm{v}$ ) mixture, and their contents were estimated gravimetrically according to the previous report [24]. The total carbohydrate content of the microalgae was measured by the phenol-sulfuric acid method [29].

\section{Fatty acid profiles}

The fatty acid profiles of the microalgae powder were analyzed by two steps including preparation of fatty acids methyl ester (FAME) and Gas ChromatographyMass Spectrometry analysis (GC-MS) [24]. The samples were microalgae harvested before dark cultivation and after N-rich or N-deficient dark cultivation. Firstly, a one-step extraction transesterification method [30] with minor modification was employed to prepare FAME, which was carefully collected and analyzed with GC-MS (Trace GC-DSQII, Thermo Fisher). The compounds were identified by reference to the NIST Mass Spectral Database and quantified by the area normalization method.

\section{Important properties}

The loss in the biomass concentration for $12 \mathrm{~h}$ in darkness (loss in biomass) was calculated in percentage via Eq. 1:

$$
\text { Loss in biomass }(\%)=\left(X_{\mathrm{I}}-X_{\mathrm{F}}\right) \times 100 / X_{\mathrm{I}}
$$

where $X_{\mathrm{I}}\left(\mathrm{mg} \mathrm{L}^{-1}\right)$ and $X_{\mathrm{F}}\left(\mathrm{mg} \mathrm{L}^{-1}\right)$ are the initial and final biomass concentrations in the broths cultivated for $12 \mathrm{~h}$ in darkness, respectively.

The percentage of gain in lipid content for $12 \mathrm{~h}$ in darkness (gain in lipid content) was calculated via Eq. 2:

$$
\text { Gain in lipid content }(\%)=\left(L_{\mathrm{F}}-L_{\mathrm{I}}\right) \times 100 / L_{\mathrm{I}}
$$

where $L_{\mathrm{I}}(\%)$ and $L_{\mathrm{F}}(\%)$ are initial and final lipid contents in cells cultivated for $12 \mathrm{~h}$ in darkness.

The percentage of loss in carbohydrate content for $12 \mathrm{~h}$ in darkness (loss in carbohydrate content) was calculated via Eq. 3:

Loss in carbohydrate content $(\%)=\left(C_{\mathrm{I}}-C_{\mathrm{F}}\right) \times 100 / C_{\mathrm{I}}$

where $C_{\mathrm{I}}(\%)$ and $C_{\mathrm{F}}(\%)$ are initial and final carbohydrate contents in cells cultivated for $12 \mathrm{~h}$ in darkness.

The net lipid accumulation defined as variation of lipid concentrations for $12 \mathrm{~h}$ in darkness was calculated via Eq. 4:

$$
\text { Lipid accumulation }\left(\mathrm{mg} \mathrm{L}^{-1}\right)=X_{\mathrm{F}} \times L_{\mathrm{F}}-X_{\mathrm{I}} \times L_{\mathrm{I}}
$$

where $X_{\mathrm{I}} \times L_{\mathrm{I}}\left(\mathrm{mg} \mathrm{L}^{-1}\right)$ and $X_{\mathrm{F}} \times L_{\mathrm{F}}\left(\mathrm{mg} \mathrm{L}^{-1}\right)$ are initial and final lipid concentrations in photobioreactor for $12 \mathrm{~h}$ in darkness.

The gain in lipid concentration defined as variation percentage of lipid concentrations during $12 \mathrm{~h}$ darkness was calculated via Eq. 5:

Gain in lipid concentration (\%)

$$
=\left(X_{\mathrm{F}} \times L_{\mathrm{F}}-X_{\mathrm{I}} \times L_{\mathrm{I}}\right) \times 100 / X_{\mathrm{I}} \times L_{\mathrm{I}}
$$

Based on the equations deduced by Hoekman et al. [21], the biodiesel properties were predicted as follows:

Average degree of unsaturation (ADU) of microalgal oil was computed from fatty acid profiles via Eq. 6 .

$$
\mathrm{ADU}=\sum M \times Y_{i}
$$

where $Y_{i}$ is the mass fraction of each fatty acid constituent $i$, and $M$ is the number of carbon-carbon double bonds in each fatty acid molecule.

The relationships between biodiesel ADU and other critical fuel properties, namely kinematic viscosity (KV, $\mathrm{mm}^{2} \mathrm{~s}^{-1}$ at $40{ }^{\circ} \mathrm{C}$ ), specific gravity (SG, $\mathrm{kg} \mathrm{L}^{-1}$ ), cloud point $\left(\mathrm{CP},{ }^{\circ} \mathrm{C}\right)$, cetane number $(\mathrm{CN})$ and iodine value (IV, $\left.\mathrm{gI}_{2} / 100 \mathrm{~g}\right)$, are shown in Eqs. 7-11 [24, 25]: 


$$
\begin{array}{cc}
y_{1}=-0.6316 x+5.2065 & R^{2}=0.6704 \\
y_{2}=0.0055 x+0.8726 & R^{2}=0.6644 \\
y_{3}=-13.356 x+19.994 & R^{2}=0.6809 \\
y_{4}=-6.6684 x+62.876 & R^{2}=0.8049 \\
y_{5}=74.373 x+12.71 & R^{2}=0.9484
\end{array}
$$

where $y_{1}, y_{2}, y_{3}, y_{4}$ and $y_{5}$ are KV, SG, CP, CN and IV, respectively, and $x$ is biodiesel ADU.

\section{Statistical analysis}

The respective differences between losses in biomass, gains in lipid content, amounts of lipid accumulation, and fatty acid compositions were assessed using one-way analysis of variance (ANOVA). A difference was considered statistically significant when $p<0.05$ according to Duncan's tests.

\section{Results}

\section{Effect of blending mode}

Table 2 showed the percentage changes of the biomass concentration and lipid content, lipid accumulation in SDEC-3M, and dissolved oxygen in the broths in response to different blending modes during $12 \mathrm{~h}$ darkness. Both loss in biomass and gain in lipid content in SDEC-3M obtained in the aeration mode were much higher than those in other two modes. Further, because the gain in lipid content was much higher than the biomass loss, lipids were accumulated in the shaking and aeration modes, and the highest lipid accumulation of $31.20 \pm 6.59 \mathrm{mg} \mathrm{L}^{-1}$ was obtained in the aeration mode.

Due to the closed cultivation, the standing mode meant no mixing and oxygenizing, while the shaking mode was supplied with mixing but no oxygenizing. Due to absence of mixing in the standing mode, most microalgae cells in

\begin{tabular}{|c|c|c|c|}
\hline \multirow[t]{2}{*}{ Parameter } & \multicolumn{3}{|c|}{ Blending mode } \\
\hline & Standing & Shaking & Aeration \\
\hline Loss in biomass (\%) & $0.64 \pm 0.14^{\mathrm{a}}$ & $1.64 \pm 0.13^{\mathrm{a}}$ & $7.14 \pm 0.98^{b}$ \\
\hline Gain in lipid content (\%) & $0.57 \pm 0.90^{\mathrm{a}}$ & $8.17 \pm 2.22^{\mathrm{a}}$ & $48.25 \pm 10.14^{b}$ \\
\hline $\begin{array}{l}\text { Lipid accumulation } \\
\left(\mathrm{mg} \mathrm{L}^{-1}\right)\end{array}$ & $-0.07 \pm 0.62^{a}$ & $5.30 \pm 1.79^{a}$ & $31.20 \pm 6.59^{b}$ \\
\hline Dissolved oxygen $\left(\mathrm{mg} \mathrm{L}^{-1}\right)$ & $1.67 \pm 0.15$ & $0.03 \pm 0.06$ & $6.83 \pm 0.06$ \\
\hline
\end{tabular}

Table 2 Loss in biomass, gain in lipid content and lipid accumulation in SDEC-3M, and dissolved oxygen in broths in response to different blending modes during $12 \mathrm{~h}$ darkness

Each entry indicates the mean \pm S.D., $n=3$, measured from three independent cultures. Data in the same row followed by different letters are significantly different by Duncan's test $(p<0.05)$ the bottom of flasks precipitated and few suspended cells were observed in broths after $12 \mathrm{~h}$ darkness. As a result of no oxygenizing, almost zero DO was recorded in the broths for the shaking mode (Table 2). In aeration mode the two functions occurred simultaneously. The results show that mixing and oxygenizing, through which cells could receive nutrients and oxygen, are both necessary for cell activity and lipid accumulation, but significance analysis showed that the latter is much more important. In darkness, thus, aeration is essential to accumulate lipid in SDEC-3M.

\section{Effect of $\mathrm{CO}_{2}$ level}

Figure 1 showed the percentage changed in the biomass concentration and lipid content, and lipid accumulation in SDEC-3M in response to different $\mathrm{CO}_{2}$ levels during $12 \mathrm{~h}$ darkness. No significant differences were observed between losses in biomass under $0.04 \% \mathrm{CO}_{2}$ (air), $1 \%$ $\mathrm{CO}_{2}, 5 \% \mathrm{CO}_{2}$, or $15 \% \mathrm{CO}_{2}$, while these were significantly lower than the losses occurring under $25 \% \mathrm{CO}_{2}$. Some dead cell walls were observed in broths aerated with $25 \%$ $\mathrm{CO}_{2}$, but were scarce in other treatments. This indicated that the reason causing increase of biomass loss was not more active respiration but more death and autolysis of some microalgae cells. This could imply that the tolerance of SDEC-3M to $\mathrm{CO}_{2}$ above $15 \%$ was poorer.

The observation that higher lipid contents were obtained under higher $\mathrm{CO}_{2}$ level was consistent with the reported findings under continuous illumination or light/ dark cycles [20]. It showed that a high $\mathrm{CO}_{2}$ level stimulated lipid accumulation in microalgae in both light and darkness. High $\mathrm{CO}_{2}$ level is considered a stress condition to promote lipid accumulation for some algae species

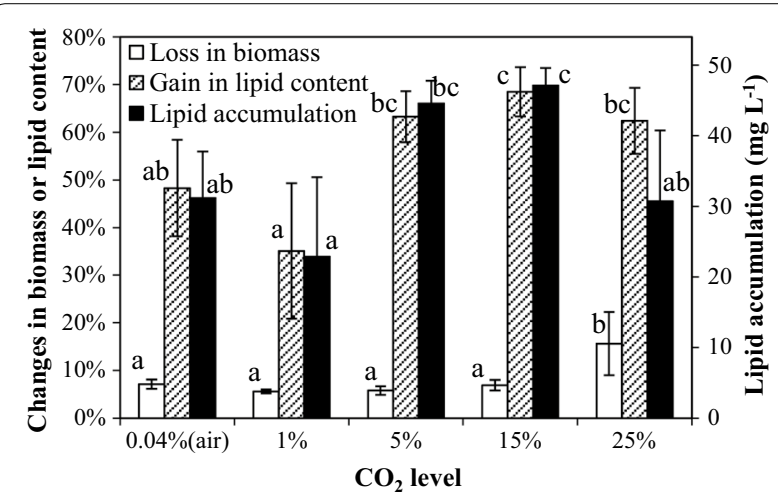

Fig. 1 Loss in biomass, gain in lipid content and lipid accumulation in SDEC-3M in response to different $\mathrm{CO}_{2}$ levels during $12 \mathrm{~h}$ darkness. Each entry indicates the mean \pm S.D., $n=3$, measured from three independent cultures. Data for the same type of parameter (with the same shading) followed by different letters are significantly different by Duncan's test $(p<0.05)$ 
$[3,31]$. The other possible explanation is that lower $\mathrm{O}_{2}$ partial pressure in higher $\mathrm{CO}_{2}$ mixtures lowers the $\mathrm{DO}$ in the broths, which is lethal to algal cells [1] and eventually decreases the lipid content in microalgae cells [32].

No significant differences were found between gains in lipid content under $5 \%, 15 \%$, and $25 \% \mathrm{CO}_{2}$. It indicated that the effect of the $\mathrm{CO}_{2}$ level could be neglected when above 5\%. Moreover, it was observed that gain in lipid content with air was higher than that under $1 \% \mathrm{CO}_{2}$. A possible reason is that $\mathrm{SDEC}-3 \mathrm{M}$ is a high- $\mathrm{CO}_{2}$-requiring (HCR) mutant [27], for which low $\mathrm{CO}_{2}$ level (as in air) is a stress condition that also stimulates lipid accumulation in cells. Thus, high gain in lipid content and low loss in biomass coexisted under 5 to $15 \% \mathrm{CO}_{2}$, which is optimal for lipid production (no significant difference). The highest lipid accumulation of $47.13 \pm 2.47 \mathrm{mg} \mathrm{L}^{-1}$ was obtained with $15 \% \mathrm{CO}_{2}$.

\section{Effect of aeration rate}

Figure 2 showed the percentage changed in the biomass concentration and lipid content, and lipid accumulation in SDEC-3M in response to different aeration rates during $12 \mathrm{~h}$ darkness. No significant differences were observed between loss in biomass at different aeration rates, except at 'no aeration' and $0.32 \mathrm{vvm}$ aeration. A possible reason is that the 'no aeration' condition inhibited cells' respiratory activity with an absence of mixing and oxygenation ("Effect of blending mode" in section), while the higher aeration rate of $0.32 \mathrm{vvm}$ might damage microalgal cells due to intense turbulence [28].

A moderate aeration rate of $0.10 \mathrm{vvm}$ resulted in the maximum lipid content, implying that a moderate aeration rate favors lipid accumulation in darkness. Similar results were also observed in darkness [20] or in light $[28,33]$ in previous research. This could be considered as a reason that both inefficient mixing at low aeration rate that limits microalgal uptake of nutrients and the damage at high aeration rate to the cells by intense turbulence each inhibits the metabolism of lipid synthesis [28].

Because of the slight difference of loss in biomass at different aeration rates, lipid accumulation depended more on gain in lipid content. This result was also confirmed through the same results by performing ANOVA on gain in lipid content and lipid accumulation (Fig. 2). Therefore, the highest lipid accumulation of $47.13 \pm 2.47 \mathrm{mg} \mathrm{L}^{-1}$ was obtained at $0.10 \mathrm{vvm}$, with significantly higher gain in lipid content. Generally, the moderate aeration rate of $0.10 \mathrm{vvm}$ was the optimal condition.

\section{Effect of $\mathrm{NO}_{3}{ }^{-}-\mathrm{N}$ concentration and soil extract in media}

Figure 3 showed the percentage changed in the biomass concentration, lipid content and carbohydrate content, and lipid accumulation in SDEC-3M in response to different media during $12 \mathrm{~h}$ darkness. Loss in biomass fluctuated in the range of $4-8 \%$ in different media. It show that the short-term effect of $\mathrm{NO}_{3}{ }^{-} \mathrm{N}$ concentrations and soil extract on biomass loss in darkness is limited.

Even in darkness, as Fig. 3 shows, the loss of lipid contents were reversed from $-6.66 \pm 3.22 \%$ under N-deficiency to $82.86 \pm 5.05 \%$ under $\mathrm{N}$-rich condition, so that net nightly lipid accumulation was achieved. Significant higher gains in lipid contents and lipid accumulations were obtained under relatively low $\mathrm{NO}_{3}{ }^{-} \mathrm{N}$ concentrations (in SE2, SE3, and SE4 medium), rather than under

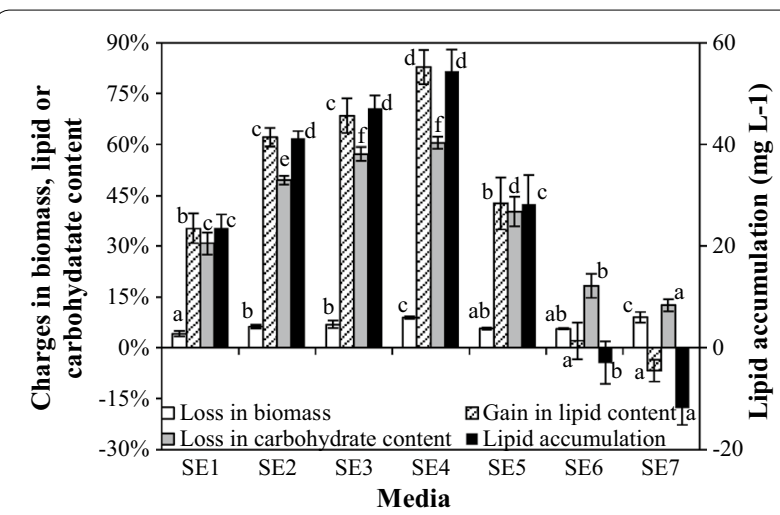

Fig. 3 Loss in biomass, gain in lipid content, loss in carbohydrate content and lipid accumulation in SDEC-3M in response to different media during $12 \mathrm{~h}$ darkness. The $\mathrm{NO}_{3}{ }^{-}-\mathrm{N}$ concentrations and absence or presence of soil extract for each medium is given in Table 1. Each entry indicates the mean \pm S.D., $n=3$, measured from three independent cultures. Data for the same type of parameter (with the same shading) followed by different letters are significantly different by Duncan's test $(p<0.05)$ 
completely $\mathrm{N}$-free conditions (in SE1 medium). Although it is well known that large amount of lipids can be accumulated in microalgae under $\mathrm{N}$-deficiency [34], the relatively low nitrogen concentration could be more favorable to lipid accumulation in some microalgae species, which were reported by some previous researchers $[20,35,36]$. Our findings confirm that the conclusion is also valid for endogenous lipid accumulation by microalgae cultivated in darkness. These phenomena may be caused by the reason that nitrogen level should be low enough to trigger the metabolism towards lipid in cells [37], and not to suspending the synthesis of the vital enzymes related to lipid synthesis [19]. As the results showed, relatively low amounts of nitrogen, such as 5 to $10 \mathrm{mg} \mathrm{L}{ }^{-1} \mathrm{NO}_{3}^{-}-\mathrm{N}$, is optimal, and the highest gain in lipid content of $82.86 \pm 5.05 \%$ and greatest lipid accumulation of $54.49 \pm 4.21 \mathrm{mg} \mathrm{L}^{-1}$ were obtained in SE4 medium with $6.52 \mathrm{mg} \mathrm{L}^{-1} \mathrm{NO}_{3}{ }^{-}-\mathrm{N}$.

As Fig. 3 shows, carbohydrate contents in SDEC-3M in seven media declined in varying degrees. Interestingly, in media with more or less nitrogen, loss in carbohydrate content was significantly lessened, and gain in lipid content and lipid accumulation had the same trend, even though the former was not like the latter two showing negative values in $\mathrm{N}$-rich media. The highest loss in carbohydrate content of $60.47 \pm 1.74 \%$ was found in SE4, in which highest gain in lipid content and lipid accumulation were obtained.

Besides nitrogen, some other ingredients were added to the media with the soil extract. To investigate the possible interference of these ingredients, the results obtained in SE3 medium with added soil extract but without additional $\mathrm{NaNO}_{3}$ were compared with those for SE2 medium with equivalent $\mathrm{NO}_{3}{ }^{-}-\mathrm{N}$. The attained lipid content of $68.47 \pm 5.18 \%$ in SE3 medium was slightly higher than that of $62.14 \pm 2.72 \%$ in SE2 medium, but there were no significant differences between them $(p>0.05)$. The same trend was observed between lipid accumulations in SE2 medium and SE3 medium. The results show that the positive effects of other ingredients in soil extract on lipid accumulation were not significant, compared with the effect of nitrogen.

\section{Effect of temperature}

Figure 4 showed the percentage changed in the biomass concentration and lipid content, and lipid accumulation in SDEC-3M in response to different temperatures imposed while culturing for $12 \mathrm{~h}$ in darkness. The biomass loss increased as temperature increased, and the highest loss was $22.21 \pm 4.71 \%$ at $40{ }^{\circ} \mathrm{C}$, when a few dead cells walls were observed in the broths. It indicated that the SDEC-3M cells were more active at higher temperatures, but are not tolerant to temperatures beyond $40^{\circ} \mathrm{C}$.

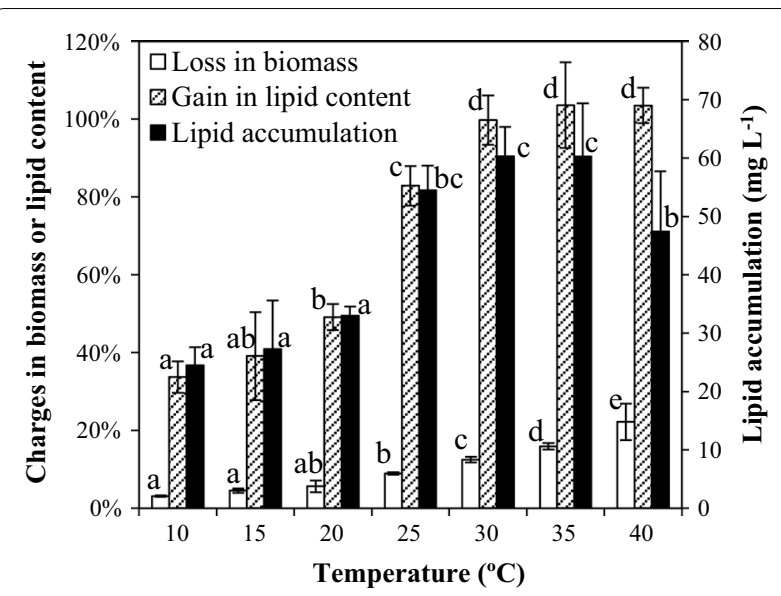

Fig. 4 Loss in biomass, gain in lipid content and lipid accumulation in SDEC-3M in response to different temperatures during $12 \mathrm{~h}$ darkness. Each entry indicates the mean \pm S.D., $n=3$, measured from three independent cultures. Data for the same type of parameter (with the same shading) followed by different letters are significantly different by Duncan's test $(p<0.05)$

Whether in low temperatures range $\left(10-20{ }^{\circ} \mathrm{C}\right)$ or high temperatures range $\left(25-40{ }^{\circ} \mathrm{C}\right)$, gain in lipid content slightly rose with increasing temperatures, while between those two ranges it dramatically increased from $49.14 \pm 3.37 \%\left(20{ }^{\circ} \mathrm{C}\right)$ to $85.26 \pm 5.11 \%\left(25{ }^{\circ} \mathrm{C}\right)$, which yields a statistically significant difference. In 25 to $40{ }^{\circ} \mathrm{C}$, the lipid contents doubled. Thus, the highest lipid accumulation of $60.32 \pm 5.03$ and $60.25 \pm 9.14 \mathrm{mg} \mathrm{L}^{-1}$ was obtained at 30 and $35^{\circ} \mathrm{C}$ (no significant difference), even though losses in biomass were up to $12.48 \pm 0.73 \%$ and $15.94 \pm 0.82 \%$. Due to higher loss in biomass, lipid accumulation was lower at the highest temperature $\left(40^{\circ} \mathrm{C}\right)$.

Previous studies confirmed that the effect of nutrient limitation on lipid content in cells is more significant than the effect of temperature stress $[2,15]$. In the present study, although gains in lipid content were improved from $33.76 \pm 4.06 \%$ to $103.59 \pm 11.02 \%$ through adjusting temperature, by comparison, as the more dominant contribution, $\mathrm{N}$ - deficiency reversed the loss of lipid contents under $\mathrm{N}$-rich condition (from $-6.66 \pm 3.22 \%$ to $82.86 \pm 5.05 \%$ ). However, it is important to find a wide temperature range suitable for lipid production, after all it is difficult to control temperature in outdoor cultivation $[1,38]$. The evidence that the lipid contents in SDEC-3M were greatly increased across a wide range of 'high' temperatures suggests it is an outstanding candidate for lipid production.

\section{Effect of biomass concentration}

Figure 5 showed the percentage changed in the biomass concentration and lipid content, and lipid accumulation in SDEC-3M in response to initial biomass concentration for $12 \mathrm{~h}$ in darkness. No significant differences of losses 


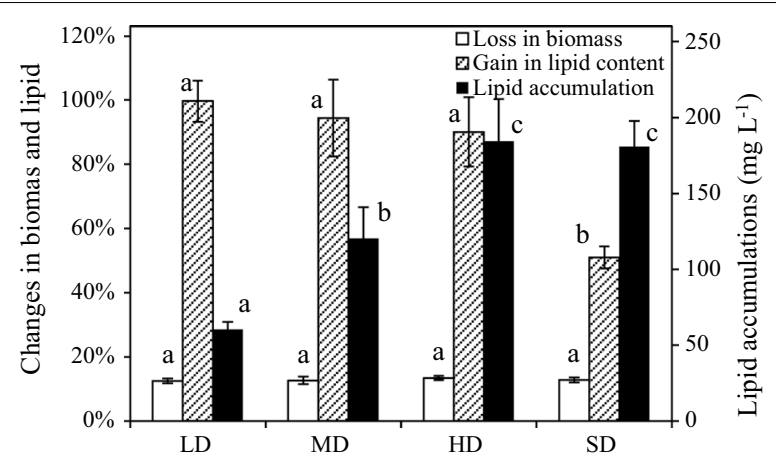

Fig. 5 Loss in biomass, gain in lipid content and lipid accumulation in SDEC-3M in low, medium, high and super-high-density cultivation (presented as LD, MD, HD and SD) during $12 \mathrm{~h}$ darkness. Each entry indicates the mean \pm S.D., $n=3$, measured from three independent cultures. Data for the same type of parameter (with the same shading) followed by s are significantly different by Duncan's test $(p<0.05)$

in biomass were observed between in different density cultivation. This indicated that the proportion of biomass loss was scarcely affected by the cultivation density.

As Fig. 5 shows, gain in lipid content significantly declined when biomass concentration was over $2500 \mathrm{mg} \mathrm{L}^{-1}$ (SD). Based on higher initial biomass concentration, however, the higher lipid accumulations of approximate $180 \mathrm{mg} \mathrm{L}^{-1}$ were both obtained in HD and SD cultivation, without significant differences between them. The lipid accumulations in SD and HD were obtained by $13.40 \%$ or $12.79 \%$ of loss in biomass and $90.14 \%$ or $50.97 \%$ of gain in lipid content, respectively. Therefore, in terms of gain in lipid concentration. $31.66 \pm 2.98 \%$ in SD was considerably lower than $64.66 \pm 9.64 \%$ in HD. Obviously, higher cultivation density can increase lipid production efficiency of bioreactor, but will be counteracted by decline of lipid content when the cultivation density was higher than $2500 \mathrm{mg} \mathrm{L}^{-1}$. Microalgae biomass concentrations generally remain at 2 to $8 \mathrm{~g} \mathrm{~L}^{-1}$ in closed photoautotrophic systems [6]. Thus, the optimal biomass concentration (approximately $2500 \mathrm{mg} \mathrm{L}^{-1}$ ) is maintained by promoting microalgal growth rate in daytime and optimizing medium renewal rate is a key in outdoor cultivation.

\section{Fatty acid profiles}

Table 3 showed the fatty acid profiles of lipid in SDEC$3 \mathrm{M}$ before and after $\mathrm{N}$-rich (SE7 medium) and N- deficient (in SE4 medium) $12 \mathrm{~h}$ dark cultivation. C16-C18 fatty acids (16:0, 16:1, 16:2, 18:0, 18:1, 18:2 and 18:3) suitable for biodiesel production [24, 39] were all higher than $95 \%$ and $16: 0$ was the most prevalent constituent in the three samples, followed by $18: 1$ and 18:2. ANOVA showed that 18:1 underwent statistically significantly increased, 16:0 and 18:3 underwent statistically significant decreased, and 18:2 and non-C16/C18 fatty acids (other) exhibited no statistically significant change under both conditions, while 16:1 and 18:0 changed more during $\mathrm{N}$-deficient cultivation than they did during $\mathrm{N}$-rich cultivation. The results that the significant effect of nutrient limitation on fatty acid profiles were also found in some previous studies $[18,22,40]$.

\section{Discussion}

Feasibility of nightly endogenous lipid accumulation

Under the photoautotrophic mode, the management of the stress conditions, especially $\mathrm{N}$-deficiency are common strategies for improving lipid accumulation $[5,13$, $16,20,41]$. In the present study, similar results occurring

Table 3 Fatty acid profiles of lipids derived from SDEC-3M samples before and after 12 h N-rich or $\mathbf{N}$-deficient cultivation in darkness

\begin{tabular}{lccc}
\hline Lipid number & \multicolumn{2}{l}{ Relative prevalence } & \\
\cline { 2 - 4 } & Before cultivation & After N-rich cultivation & After N-deficient cultivation \\
\hline $16: 0$ & $47.84 \pm 1.52 \%^{\mathrm{b}}$ & $43.23 \pm 1.47 \%^{\mathrm{a}}$ & $43.20 \pm 1.21 \%^{\mathrm{a}}$ \\
$16: 1$ & $1.80 \pm 0.88 \%^{\mathrm{b}}$ & $0.54 \pm 0.35 \%^{\mathrm{a}}$ & $0.95 \pm 0.41 \%^{\mathrm{ab}}$ \\
$16: 2$ & $3.62 \pm 0.66 \%^{\mathrm{b}}$ & $4.97 \pm 0.30 \%^{\mathrm{c}}$ & $2.57 \pm 0.55 \%^{\mathrm{a}}$ \\
$18: 0$ & $1.16 \pm 1.16 \%^{\mathrm{a}}$ & $1.24 \pm 1.24 \%^{\mathrm{a}}$ & $2.48 \pm 2.48 \%^{\mathrm{b}}$ \\
$18: 1$ & $8.11 \pm 1.35 \%^{\mathrm{a}}$ & $18.75 \pm 2.67 \%^{\mathrm{b}}$ & $20.02 \pm 1.04 \%^{\mathrm{b}}$ \\
$18: 2$ & $19.59 \pm 1.43 \%^{\mathrm{a}}$ & $19.08 \pm 2.78 \%^{\mathrm{a}}$ & $18.22 \pm 0.66 \%^{\mathrm{a}}$ \\
$18: 3$ & $13.72 \pm 0.87 \%^{\mathrm{b}}$ & $8.78 \pm 0.18 \%^{\mathrm{a}}$ & $8.67 \pm 0.92 \%^{\mathrm{a}}$ \\
Other & $4.17 \pm 0.4 \%^{\mathrm{a}}$ & $3.41 \pm 0.5 \%^{\mathrm{a}}$ & $3.89 \pm 0.6 \%^{\mathrm{a}}$ \\
\hline
\end{tabular}

Each entry indicates the mean \pm S.D., $n=3$, measured from three independent cultures. Data in the same row followed by different letters are significantly different by Duncan's test $(p<0.05)$ 
at night confirm the feasibility of nightly endogenous lipid accumulation. Due to no carbon source and energy source supplied by photosynthesis or organic matter in media, triggering endogenous lipid accumulation should be the only one way to minimize, even reverse nightly lipid loss caused by light/dark cycle. In consideration of growth ceasing in darkness, growth inhibition caused by stress conditions is disappeared at night. Based on these, the light-NR/dark-ND process can eliminates the negative effects of nighttime on lipid production, and then increases lipid productivity.

\section{Pathway of nightly endogenous lipid accumulation}

It is observed that carbon and energy fixed by photosynthesis are shifted from starch synthesis to lipid synthesis under stress conditions, which pathway and mechanism are largely clearer [33, 37, 42, 43]. Relative to photosynthetic lipid accumulation, few nightly endogenous lipid accumulation in microalgae cells have been researched. The dramatic improvement of lipid content [20] and a conversion from sugar to lipids [41] in Chlorella were observed under $\mathrm{N}$-deficiency and darkness. In present study, it is found that loss in carbohydrate content had the same trend as gain in lipid content in media with different nitrogen concentrations, and their maximum value were both obtained under relatively low nitrogen concentrations. Considering that the nightly respiration of microalgae cells is mainly supported by starch, rather than lipid [44] and abundant carbohydrates in SDEC-3M accumulating under $\mathrm{N}$-rich conditions (more than $40 \%$ of biomass), the results confirm that the energy sources and carbon sources used for lipid accumulation are from carbohydrates. However, the detailed knowledge of endogenous pathway from carbohydrates to lipid is limited, which forces us to test microalgal strains one by one. Hence, it is necessary to clarify the pathway and mechanism of nightly endogenous lipid accumulation.
Optimal conditions and maximum yield of nightly endogenous lipid accumulation

After one condition after another compared, the optimal condition for more lipid accumulation are followed: aeration mode, moderate aeration rate $(0.10 \mathrm{vvm})$, higher $\mathrm{CO}_{2}$ level (15\%), relatively low $\mathrm{NO}_{3}{ }^{-} \mathrm{N}$ concentrations $\left(5-10 \mathrm{mg} \mathrm{L}^{-1}\right)$, higher temperature $\left(30-35^{\circ} \mathrm{C}\right)$ and higher density cultivation (approximate $2500 \mathrm{mg} \mathrm{L}^{-1}$ ). These results do not show that more unfavorable conditions are, the more lipid microalgal can be accumulated. The reasons should be that too severe conditions lead to cell death and suspension of lipid synthesis. Under optimal conditions, over $180 \mathrm{mg} \mathrm{L}^{-1}$ was accumulated during $12 \mathrm{~h}$ darkness, with $13.40 \%$ of loss in biomass, $90.14 \%$ of gain in lipid content and $64.66 \%$ of gain in lipid concentration. The result exceed lipid productivities of the most promising oleaginous microalgae under photoautotrophic culturing [2, 16, 28, 38, 40, 45], although nightly biomass loss is still inevitable. The result shows the great potential of SDEC-3M and light-NR/dark-ND batch process in application for biodiesel production.

\section{Biodiesel performance derived from nightly endogenous lipid}

Whether lipid in SDEC-3M are commercial feedstocks for biodiesel production depends on not only lipid yield, but also lipid quality. In many studies, the biodiesel performances were analyzed by properties derived by fatty acid profiles $[18,19,24,25]$. According to Eqs. 7 to 11, biodiesel ADU and five other critical fuel properties (KV, SG, CP, CN and IV), can be directly or indirectly calculated from fatty acid profiles. As shown in Table 4, due to the change in fatty acid profiles, AUD, SG and IV decreased, whereas $\mathrm{KV}, \mathrm{CP}$, and $\mathrm{CN}$ rose during $12 \mathrm{~h}$ dark cultivation. All changes were more significant under $\mathrm{N}$-deficient conditions. Because $\mathrm{CN}, \mathrm{IV}$, and $\mathrm{CP}$ relate to combustion performance, oxidation stability, and low temperature performance of biodiesel, respectively, while

Table 4 Six fuel properties of biodiesel-ADU, KV, SG, CP, CN and IV-derived from SDEC-3M samples before and after $12 \mathrm{~h}$ N-deficient or N-rich cultivation in darkness, and their standards in China, the USA, and Europe

\begin{tabular}{|c|c|c|c|c|c|c|}
\hline \multirow[t]{2}{*}{ Biodiesel property } & \multicolumn{3}{|l|}{ Empirical estimation } & \multicolumn{3}{|c|}{ Standard value [19] } \\
\hline & Before cultivation & After N-rich cultivation & $\begin{array}{l}\text { After } \mathrm{N} \text {-deficient } \\
\text { cultivation }\end{array}$ & $\begin{array}{l}\text { CN (GB/T } \\
20828)\end{array}$ & $\begin{array}{l}\text { USA (ASTM } \\
\text { D6751) }\end{array}$ & $\begin{array}{l}\text { Europe (EN } \\
14214)\end{array}$ \\
\hline $\mathrm{KV} 40^{\circ} \mathrm{C}\left(\mathrm{mm}^{2} \mathrm{~s}^{-1}\right)$ & $4.56 \pm 0.02$ & $4.59 \pm 0.02$ & $4.62 \pm 0.02$ & 4.39 to 4.95 & 1.9 to 6.0 & 1.9 to 6.0 \\
\hline $\mathrm{SG}\left(\mathrm{kg} \mathrm{L}^{-1}\right)$ & $0.8782 \pm 0.0002$ & $0.8779 \pm 0.0002$ & $0.8777 \pm 0.0002$ & 0.875 to 0.880 & 0.82 to 0.90 & 0.87 to 0.89 \\
\hline $\mathrm{CP}\left({ }^{\circ} \mathrm{C}\right)$ & $6.41 \pm 0.47$ & $7.03 \pm 0.49$ & $7.69 \pm 0.41$ & 2.83 to 14.66 & Report & Report \\
\hline $\mathrm{CN}$ & $56.09 \pm 0.23$ & $56.4 \pm 0.25$ & $56.73 \pm 0.21$ & 54.31 to 59.29 & $\min 49$ & $\min 47$ \\
\hline $\mathrm{IV}\left(\mathrm{gl}_{2} / 100 \mathrm{~g}\right)$ & $88.37 \pm 2.6$ & $84.9 \pm 2.75$ & $81.24 \pm 2.29$ & 42.41 to 108.27 & - & - \\
\hline ADU & $1.02 \pm 0.03$ & $0.97 \pm 0.04$ & $0.92 \pm 0.03$ & 0.40 to 1.28 & - & - \\
\hline
\end{tabular}


KV and SG affect emission levels and combustion performance $[4,19,24,39]$, the combustion performance, oxidation stability, and exhaust emission levels of biodiesel would be improved, but the low temperature performance would worsen following $12 \mathrm{~h}$ dark cultivation, which would be more obvious under $\mathrm{N}$-deficient conditions. Despite those changes, the biodiesel properties of all three samples still complied with the three most common biodiesel quality standards, including GB/T 20828 in China, ASTM D6751 in the USA, and EN 14214 in Europe (Table 4). The results indicate that endogenously accumulated lipid in darkness by SDEC-3M as biodiesel feedstocks are feasibility.

\section{Conclusions}

In the present study, C. vulgaris SDEC-3M was cultivated for $12 \mathrm{~h}$ in darkness. Under non-stress conditions, lipid contents dropped, which caused more than $10 \mathrm{mg} \mathrm{L}^{-1}$ of lipid loss, together with biomass loss. However, endogenous lipid accumulation triggered by stress conditions drastically increased lipid content. Based on the lipid content gain overwhelming the biomass loss, lipid loss was minimized, and even reversed. Under optimal conditions (aeration mode, moderate aeration rate, higher $\mathrm{CO}_{2}$ level, relatively low $\mathrm{NO}^{3-}-\mathrm{N}$ concentrations, higher temperature and higher density cultivation), the lipid content was elevated by $90.14 \%$ and proximately $180 \mathrm{mg} \mathrm{L}^{-1}$ net accumulated lipid (approximately 65\% increment based on initial lipid concentration) was obtained. The estimated properties complied with biodiesel standards. It indicated that lipids from SDEC-3M were suitable feedstocks for biodiesels. These findings determining the feasibility and optimal conditions of endogenous lipid accumulation in SDEC-3M in darkness, are the preliminary effort to commercialize the light-NR/dark-ND process for microalgal biodiesel production.

\section{Abbreviations \\ Light-NR/dark-ND process: a process combining a light/dark cycle in coopera- tion with an N-rich/N-deficient cycle; SDEC: Shandong Provincial Engineer- ing Centre on Environmental Science and Technology; UV: ultraviolet; DO: dissolved oxygen; LD: low-density; MD: mid-density; HD: high-density; SD: super-high density; FAME: fatty acids methyl ester; GC-MS: Gas Chromatog- raphy-Mass Spectrometry analysis; $\mathrm{ADU}$ : average degree of unsaturation; $\mathrm{KV}$ : kinematic viscosity; SG: specific gravity; CP: cloud point; CN: cetane number; IV: iodine value; Eqs: equations; ANOVA: one-way analysis of variance; S.D.: standard deviation.}

\section{Acknowledgements}

We are grateful for the financial assistance for this investigation provided by National Science Fund for Excellent Young Scholars (51322811), National Key Research and Development planning of China (2017YFF0209903), Shandong Province Water Conservancy research and Technology Extension Project (SDSLKY201812), University Science and Technology Project of Shandong Province (J16LD06) and the Innovation Team of the Co-Innovation Center for Green Building of Shandong Province in Shandong Jianzhu University. We are indebted to Shandong Provincial Engineering Centre on Environmental
Science and Technology and Prof. Pei for providing us the microalgal strain (SDEC-3M).

\section{Authors' contributions}

$F Q$ and HP designed the research; HP was in charge of experiments; FQ, GM and $\mathrm{QH}$ performed research; FQ, GM and RM analyzed the data; $\mathrm{HP}$ and DW provided technical support; $\mathrm{FQ}$ wrote the manuscript; PH polished and revised the Manuscript. PH and WD made a final proof of data presented. All authors read and approved the final manuscript.

\section{Funding}

This work was funded by National Science Fund for Excellent Young Scholars (51322811), Natural Foundation of Shandong Province (ZR2019MEE104), Shandong Province Water Conservancy research and Technology Extension Project (SDSLKY201812), National Key Research and Development planning of China (2017YFF0209903) and University Science and Technology Project of Shandong Province (J16LD06).

\section{Availability of data and materials}

All data generated or analyzed during the present study are included in this published article.

\section{Ethics approval and consent to participate} Not applicable.

\section{Consent for publication}

All authors consent to the publication of the manuscript in Biotechnology for Biofuels. All authors have approved the manuscript to be published.

\section{Competing interests}

The authors declare that they have no competing interests.

\section{Author details}

${ }^{1}$ School of Municipal and Environmental Engineering, Shandong Jianzhu University, Jinan 250101, China. ${ }^{2}$ Shandong Provincial Engineering Centre on Environmental Science and Technology, Jinan 250061, China. ${ }^{3}$ School of Environmental Science and Engineering, Shandong University, Qingdao 266237, China. ${ }^{4}$ Jinan Urban Construction Group Co., Ltd, Jinan 250031, China. ${ }^{5}$ Shandong Co-innovation Center of Green Building, Jinan 250101, China.

Received: 13 January 2019 Accepted: 9 June 2019

Published online: 18 June 2019

References

1. Suali E, Sarbatly R. Conversion of microalgae to biofuel. Renew Sustain Energy Rev. 2012;16(6):4316-42.

2. Ördög $V$, Stirk WA, Bálint P, Aremu AO, Okem A, Lovász C, Molnár Z, Staden JV. Effect of temperature and nitrogen concentration on lipid productivity and fatty acid composition in three Chlorella strains. Algal Res. 2016:16:141-9.

3. Tripathi R, Singh J, Thakur IS. Characterization of microalga Scenedesmus sp. ISTGA1 for potential $\mathrm{CO}_{2}$ sequestration and biodiesel production. Renew Energy. 2015;74:774-81.

4. Chisti Y. Biodiesel from microalgae. Biotechnol Adv. 2007:25(3):294-306.

5. Chia SR, Ong HC, Chew KW, Show PL, Phang SM, Ling TC, Nagarajan D, Lee DJ, Chang JS. Sustainable approaches for algae utilisation in bioenergy production. Renew Energy. 2018;129:838-52.

6. Zhu J, Rong J, Zong B. Factors in mass cultivation of microalgae for biodiesel. Chin J Catal. 2013;34(1):80-100.

7. Kato Y, Fujihara Y, Vavricka CJ, Chang JS, Hasunuma T, Kondo A. Light/dark cycling causes delayed lipid accumulation and increased photoperiodbased biomass yield by altering metabolic flux in oleaginous Chlamydomonas sp. Biotechnol Biofuels. 2019;12:39.

8. Sharma YC, Singh V. Microalgal biodiesel: a possible solution for India's energy security. Renew Sust Energy Rev. 2017;2016(67):72-88.

9. Han F, Wang W, Li Y, Shen G, Wan M, Wang J. Changes of biomass, lipid content and fatty acids composition under a light-dark cyclic culture of 
Chlorella pyrenoidosa in response to different temperature. Biores Technol. 2013;132:182-9.

10. Ogbonna JC, Tanaka H. Night biomass loss and changes in biochemical composition of cells during light/dark cyclic culture of Chlorella pyrenoidosa. J Ferment Bioeng. 1996;82(6):558-64.

11. Wan M, Zhang J, Hou D, Fan J, Li Y, Huang J, Wang J. The effect of temperature on cell growth and astaxanthin accumulation of Haematococcus pluvialis during a light-dark cyclic cultivation. Biores Technol. 2014;167:276-83.

12. Taleb A, Legrand J, Takache H, Taha S, Pruvost J. Investigation of lipid production by nitrogen-starved Parachlorella kessleri under continuous illumination and day/night cycles for biodiesel application. J Appl Phycol. 2017:30(2):761-72.

13. Yang $L$, Chen J, Qin $S$, Zeng $M$, Jiang $Y$, Hu L, Xiao P, Hao W, Hu Z, Lei A, et al. Growth and lipid accumulation by different nutrients in the microalga Chlamydomonas reinhardtii. Biotechnol Biofuels. 2018;11:40.

14. Huete-Ortega M, Okurowska K, Kapoore RV, Johnson MP, Gilmour DJ, Vaidyanathan $\mathrm{S}$. Effect of ammonium and high light intensity on the accumulation of lipids in Nannochloropsis oceanica (CCAP 849/10) and Phaeodactylum tricornutum (CCAP 1055/1). Biotechnol Biofuels. 2018;11:60

15. Roleda MY, Slocombe SP, Leakey RJ, Day JG, Bell EM, Stanley MS. Effects of temperature and nutrient regimes on biomass and lipid production by six oleaginous microalgae in batch culture employing a two-phase cultivation strategy. Biores Technol. 2013;129:439-49.

16. Zhu S, Wang Y, Shang C, Wang Z, Xu J, Yuan Z. Characterization of lipid and fatty acids composition of Chlorella zofingiensis in response to nitrogen starvation. J Biosci Bioeng. 2015;120(2):205-9.

17. Han F, Pei H, Hu W, Zhang S, Han L, Ma G. The feasibility of ultrasonic stimulation on microalgae for efficient lipid accumulation at the end of the logarithmic phase. Algal Res. 2016;16:189-94.

18. Shekh AY, Shrivastava P, Krishnamurthi K, Mudliar SN, Devi SS, Kanade GS, Lokhande SK, Chakrabarti T. Stress-induced lipids are unsuitable as a direct biodiesel feedstock: a case study with Chlorella pyrenoidosa. Biores Technol. 2013;138:382-6.

19. Qi F, Pei H, Ma G, Zhang S, Mu R. Improving productivity and quality of biodiesel from Chlorella vulgaris SDEC-3M through customized process designs. Energy Convers Manage. 2016;129:100-7.

20. Mujtaba G, Choi W, Lee CG, Lee K. Lipid production by Chlorella vulgaris after a shift from nutrient-rich to nitrogen starvation conditions. Biores Technol. 2012;123:279-83.

21. Matich EK, Ghafari M, Camgoz E, Caliskan E, Pfeifer BA, Haznedaroglu BZ, Atilla-Gokcumen GE. Time-series lipidomic analysis of the oleaginous green microalga species Ettlia oleoabundans under nutrient stress. Biotechnol Biofuels. 2018;11:29.

22. Katiyar R, Bharti RK, Gurjar BR, Kumar A, Biswas S, Pruthi V. Utilization of de-oiled algal biomass for enhancing vehicular quality biodiesel production from Chlorella sp. in mixotrophic cultivation systems. Renew Energy. 2018;122:80-8.

23. Sun XM, Ren LJ, Bi ZQ, Ji XJ, Zhao QY, Jiang L, Huang H. Development of a cooperative two-factor adaptive-evolution method to enhance lipid production and prevent lipid peroxidation in Schizochytrium sp. Biotechnol Biofuels. 2018;11:65.

24. Song M, Pei H, Hu W, Ma G. Evaluation of the potential of 10 microalgal strains for biodiesel production. Biores Technol. 2013;141:245-51.

25. Hoekman SK, Broch A, Robbins C, Ceniceros E, Natarajan M. Review of biodiesel composition, properties, and specifications. Renew Sustain Energy Rev. 2012;16(1):143-69.

26. Francisco ÉC, Neves DB, Jacob-Lopes E, Franco TT. Microalgae as feedstock for biodiesel production: carbon dioxide sequestration, lipid production and biofuel quality. J Chem Technol Biotechnol. 2010;85(3):395-403.

27. Qi F, Pei H, Hu W, Mu R, Zhang S. Characterization of a microalgal mutant for $\mathrm{CO}_{2}$ biofixation and biofuel production. Energy Convers Manage. 2016;122:344-9.
28. Han F, Pei H, Hu W, Song M, Ma G, Pei R. Optimization and lipid production enhancement of microalgae culture by efficiently changing the conditions along with the growth-state. Energy Convers Manage. 2015;90:315-22.

29. DuBois M, Gilles KA, Hamilton JK, Rebers PA, Smith F. Colorometric method for determination of sugars and related substances. Anal Chem. 1956;28:350-6.

30. Indarti E, Majid MIA, Hashim R, Chong A. Direct FAME synthesis for rapid total lipid analysis from fish oil and cod liver oil. J Food Compos Anal. 2005;18(2-3):161-70

31. Huang Y, Cheng J, Lu H, He Y, Zhou J, Cen K. Transcriptome and key genes expression related to carbon fixation pathways in Chlorella PY-ZU1 cells and their growth under high concentrations of $\mathrm{CO}_{2}$. Biotechnol Biofuels. 2017:10:181.

32. Ota M, Kato Y, Watanabe M, Sato Y, Smith RL Jr, Rosello-Sastre R, Posten C, Inomata $\mathrm{H}$. Effects of nitrate and oxygen on photoautotrophic lipid production from Chlorococcum littorale. Biores Technol. 2011;102(3):3286-92.

33. Song M, Pei H, Hu W, Han F, Ji Y, Ma G, Han L. Growth and lipid accumulation properties of microalgal Phaeodactylum tricornutum under different gas liquid ratios. Biores Technol. 2014;165:31-7.

34. Rohit MV, Mohan SV. Tropho-metabolic transition during Chlorella sp. cultivation on synthesis of biodiesel. Renew Energy. 2016;98:84-91.

35. IIIman AM, Scragg AH, Shales SW. Increase in Chlorella strains calorific values when grown in low nitrogen medium. Enzyme Microb Technol. 2000;27(8):631-5.

36. Rodolfi L, Chini Zittelli G, Bassi N, Padovani G, Biondi N, Bonini G, Tredici MR. Microalgae for oil: strain selection, induction of lipid synthesis and outdoor mass cultivation in a low-cost photobioreactor. Biotechnol Bioeng. 2009:102(1):100-12.

37. Bellou S, Baeshen MN, Elazzazy AM, Aggeli D, Sayegh F, Aggelis G. Microalgal lipids biochemistry and biotechnological perspectives. Biotechnol Adv. 2014;32(8):1476-93.

38. Řezanka T, Nedbalová L, Lukavský J, Strǐžek A, Sigler K. Pilot cultivation of the green alga Monoraphidium sp. producing a high content of polyunsaturated fatty acids in a low-temperature environment. Algal Res. 2017;22:160-5.

39. Knothe G. Improving biodiesel fuel properties by modifying fatty ester composition. Energy Environ Sci. 2009;2(7):759-66.

40. Chen Y, XUT, Kapoore RV, Xu C, Vaidyanathan S. Influence of nutrient status on the accumulation of biomass and lipid in Nannochloropsis salina and Dunaliella salina. Energy Convers Manage. 2015;106:61-72.

41. Bellou S, Aggelis G. Biochemical activities in Chlorella sp. and Nannochloropsis salina during lipid and sugar synthesis in a lab-scale open pond simulating reactor. J Biotechnol. 2012;164(2):318-29.

42. Tan KW, Lee YK. The dilemma for lipid productivity in green microalgae: importance of substrate provision in improving oil yield without sacrificing growth. Biotechnol Biofuels. 2016;9(1):255.

43. Jia J, Han D, Gerken HG, Li Y, Sommerfeld M, Hu Q, Xu J. Molecular mechanisms for photosynthetic carbon partitioning into storage neutral lipids in Nannochloropsis oceanica under nitrogen-depletion conditions. Algal Res. 2015;7:66-77.

44. de Winter L, Cabanelas ITD, Martens DE, Wijffels RH, Barbosa MJ. The influence of day/night cycles on biomass yield and composition of Neochloris oleoabundans. Biotechnol Biofuels. 2017;10:104.

45. Calixto CD, da Silva Santana JK, Tibúrcio VP, de Pontes LdFBL, da Costa Sassi CF, da Conceição MM, Sassi R. Productivity and fuel quality parameters of lipids obtained from 12 species of microalgae from the northeastern region of Brazil. Renew Energy. 2018;115:1144-52.

\section{Publisher's Note}

Springer Nature remains neutral with regard to jurisdictional claims in published maps and institutional affiliations. 